Article

\title{
Molecular Characterization and Functional Analysis of Three Pathogenesis-Related Cytochrome P450 Genes from Bursaphelenchus xylophilus (Tylenchida: Aphelenchoidoidea)
}

Xiao-Lu Xu ${ }^{1,2}$, Xiao-Qin Wu ${ }^{1,2, *}$, Jian-Ren Ye ${ }^{1,2}$ and Lin Huang 1,2

1 Co-Innovation Center for Sustainable Forestry in Southern China, College of Forestry, Nanjing Forestry University, Nanjing 210037, China; E-Mails: xiaoluxu@163.com (X.-L.X.); jrye@njfu.edu.cn (J.-R.Y.); Lhuang@njfu.edu.cn (L.H.)

2 Jiangsu Key Laboratory for Prevention and Management of Invasive Species, Nanjing Forestry University, Nanjing 210037, China

* Author to whom correspondence should be addressed; E-Mail: xqwu@njfu.edu.cn; Tel./Fax: +86-25-8542-7427.

Academic Editor: Jan Schirawski

Received: 22 December 2014 / Accepted: 15 February 2015 / Published: 6 March 2015

\begin{abstract}
Bursaphelenchus xylophilus, the causal agent of pine wilt disease, causes huge economic losses in pine forests. The high expression of cytochrome P450 genes in B. xylophilus during infection in $P$. thunbergii indicated that these genes had a certain relationship with the pathogenic process of B. xylophilus. Thus, we attempted to identify the molecular characterization and functions of cytochrome P450 genes in B. xylophilus. In this study, full-length cDNA of three cytochrome P450 genes, $B x C Y P 33 C 9, B x C Y P 33 C 4$ and $B x C Y P 33 D 3$ were first cloned from B. xylophilus using $3^{\prime}$ and 5' RACE PCR amplification. Sequence analysis showed that all of them contained a highly-conserved cytochrome P450 domain. The characteristics of the three putative proteins were analyzed with bioinformatic methods. RNA interference (RNAi) was used to assess the functions of $B x C Y P 33 C 9, B x C Y P 33 C 4$ and $B x C Y P 33 D 3$. The results revealed that these cytochrome P450 genes were likely to be associated with the vitality, dispersal ability, reproduction, pathogenicity and pesticide metabolism of B. xylophilus. This discovery confirmed the molecular characterization and functions of three cytochrome P450 genes from B. xylophilus and provided fundamental information in elucidating the molecular interaction mechanism between B. xylophilus and its host plant.
\end{abstract}


Keywords: pine wood nematode; cytochrome P450 (CYP); rapid-amplification of cDNA ends (RACE); RNA interference (RNAi); detoxification

\section{Introduction}

As the causal agent of pine wilt disease (PWD), the pine wood nematode (PWN), Bursaphelenchus xylophilus (Steiner \& Buhrer) Nickle causes huge economic losses by devastating the pine forest and natural landscape resources in Asia, Europe and America [1-5]. In the 1980s, pine wood nematode was found in the Nanjing region of China for the first time [6]. It has now become the most serious introduced forest pest in China. Therefore, effective management strategies to control B. xylophilus are urgently needed. Yet, even though the fundamental biological characteristics of B. xylophilus, including biological morphology, life history, vectors, host species and ecology related problems have been clarified, based on classical and modern biological research, B. xylophilus' pathogenic mechanism is still uncertain. In addition, with the development of biotechnology techniques in the recent decade, much process about the molecular pathogenicity of B. xylophilus has been made [7]. Among them, a number of studies have focused on the pathogenesis-related genes of B. xylophilus, especially the cellulase [8], pectatelyase [9] and hemicelluloses genes which are closely related to the cell wall degradation. However, there are still other important pathogenesis-related genes of B. xylophilus which remain to be well characterized.

As one of the most versatile enzymes in nature, cytochrome P450 plays an important role in the metabolism of exogenous and endogenous materials and widely exists in all living organisms including protozoa, bacteria, fungi, plants, animals and humans [10,11]. Cytochrome P450 cannot only synthesize and degrade endogenous chemicals [12] such as hormones, fatty acids and steroids, but also metabolize exogenous compounds such as plant secondary metabolites, mutagen and pesticides [13], thus contributing to numerous functions, including growth, development, nutrition, and xenobiotic detoxification. More and more cytochrome P450 genes are being cloned and identified since the first cytochrome P450 gene was cloned in 1983. Recently, a large number of studies confirmed that cytochrome P450 genes from Caenorhabditis elegans [14] and some agricultural destructive insects, such as Helicover armigera (Hübner), Locusta migratoria, Tribolium castaneum (Herbst) [15-17], were associated with their growth, development, reproduction and xenobiotic detoxification. However there is still no report on cytochrome $\mathrm{P} 450$ of B. xylophilus, and whether it contributes to its functions, including vitality, dispersal ability, reproduction, pathogenicity and pesticide metabolism. The microarray analysis results [18] showed that the expression levels of three CYP450 genes from B. xylophilus, BxCYP33C9, BxCYP33C4 and BxCYP33D3, were upregulated 6.2-, 4.4-, 3.2-fold, respectively, during infection with $P$. thunbergii compared to B. xylophilus cultured on $B$. cinerea, indicating that these CYP450 genes might have a certain relationship with the pathogenic process of B. xylophilus.

Therefore, insights into the characteristics of cytochrome P450 genes and their functions in B. xylophilus pathogenic process may be helpful in better understanding the molecular interaction mechanism between B. xylophilus and its host pines. Since only partial sequences of BxCYP33C9, 
$B x C Y P 33 C 4$ and $B x C Y P 33 D 3$ were obtained from DNA microarrays results [18] and the full-length sequences had not been found after searching in the complete genome sequences, we sought to clone the full-length cDNA of the three cytochrome P450s genes using 3' and 5' RACE amplifications. In addition, we also endeavored to silence the three cytochrome P450 genes using RNAi technology in order to assess the functions of the three genes in B. xylophilus in our study. These findings not only allow us to understand the role of cytochrome P450 genes in B. xylophilus' pathogenic process, but also provide fundamental information in elucidating the molecular interaction mechanism between B. xylophilus and its host plant.

\section{Results and Discussion}

\subsection{Cloning and Sequence Analysis of Three Cytochrome P450 Genes from B. xylophilus}

3' RACE and 5' RACE PCR amplification were used to obtain the full-length cDNA sequences of $B x C Y P 33 C 9, B x C Y P 33 C 4$ and BxCYP33D3 from B. xylophilus. Sequence analysis showed that the full-length $B x C Y P 33 C 9$ cDNA was 1663 bp, including a 61-bp 5' untranslated region (UTR), a 96-bp 3' UTR, and a 1506-bp open reading frame (ORF) which encoded for 501 amino acids (Figure 1A). The full-length $B x C Y P 33 C 4$ cDNA contained 1483 bp, including a 102-bp 5' UTR, a 112-bp 3' UTR, and a 1269-bp ORF which encoded for 422 amino acids (Figure 1B). The full-length cDNA of BxCYP33D3 was 1688 bp, including a 17-bp 5' UTR, a 141-bp 3' UTR, and a 1530-bp ORF which encoded for 509 amino acids (Figure 1C). Furthermore, conserved domains of the cytochrome P450 family were found in the three deduced amino acid sequences of B. xylophilus, such as the typical heme binding loop (FxxGxxxCxG), helix-K (ExxR) and helix-C (WxxxR).

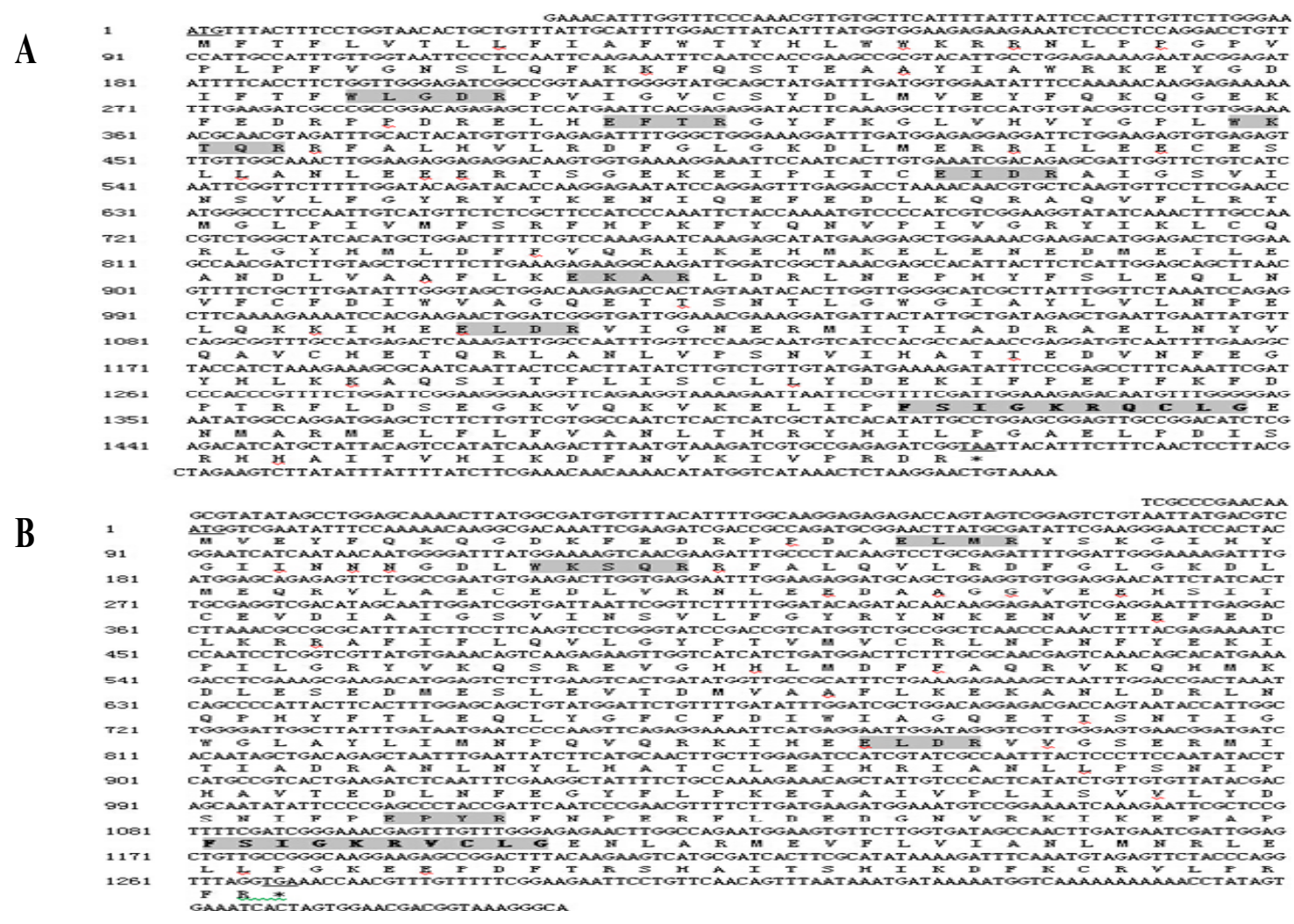

Figure 1. Cont. 


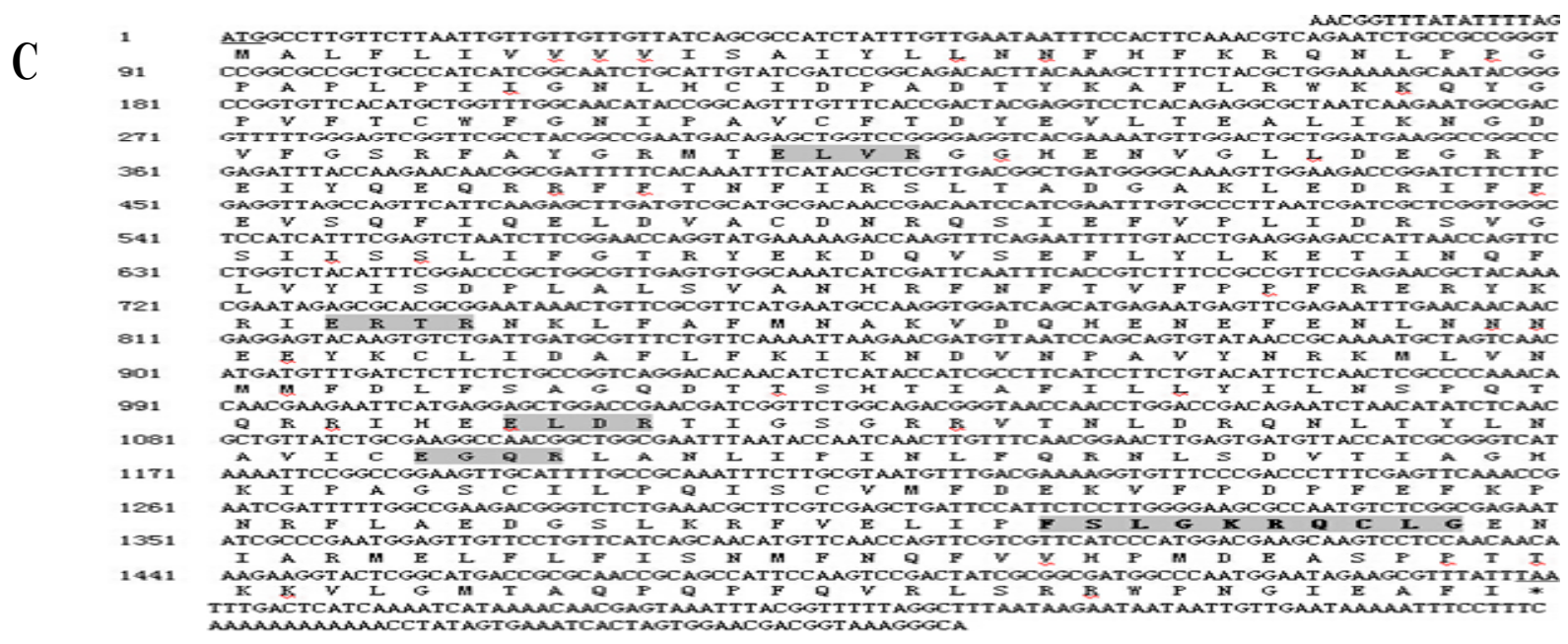

Figure 1. Full-length cDNA sequences and deduced amino acid sequences of BxCYP33C9 (A), BxCYP33C4 (B) and BxCYP33D3 (C) from B. xylophilus. Note: The initiation codon and termination codon were underlined. The conserved domains of P450s were shown in dark background. The heme-binding loop region was oblique.

\subsection{Alignment of the Three Predicted Amino Acid Sequences}

The results of Blastp showed that the deduced amino acid sequence of BxCYP33C9 exhibited a relatively high level of identity with the CYP33C9 protein of Caenorhabditis brenneri, $C$. briggsae, $C$. elegans and $C$. remanei, with their sequence percent identity at $42 \%, 42 \%, 43 \%$ and $41 \%$, respectively. BxCYP33C4 from B. xylophilus exhibited a relatively high level of identity with the CYP33C4 protein of $C$. elegans and C. briggsae, with their sequence percent identity at $39 \%$ and $35 \%$, respectively. Furthermore, the deduced BxCYP33D3 exhibited a relatively high level of identity with the CYP33D3 protein of C. elegans, C. remanei and C. briggsae, with their sequence percent identity at $36 \%, 36 \%$ and $35 \%$, respectively. On this basis, the amino acid sequences which showed relatively high homology with the predicted amino acid sequences were downloaded from NCBI, and DNAMAN software was used to carry out the multiple sequence alignments (Figure 2A-C). MEGA 6.0 software was used to construct phylogenetic trees (NJ) (Figure 2D).

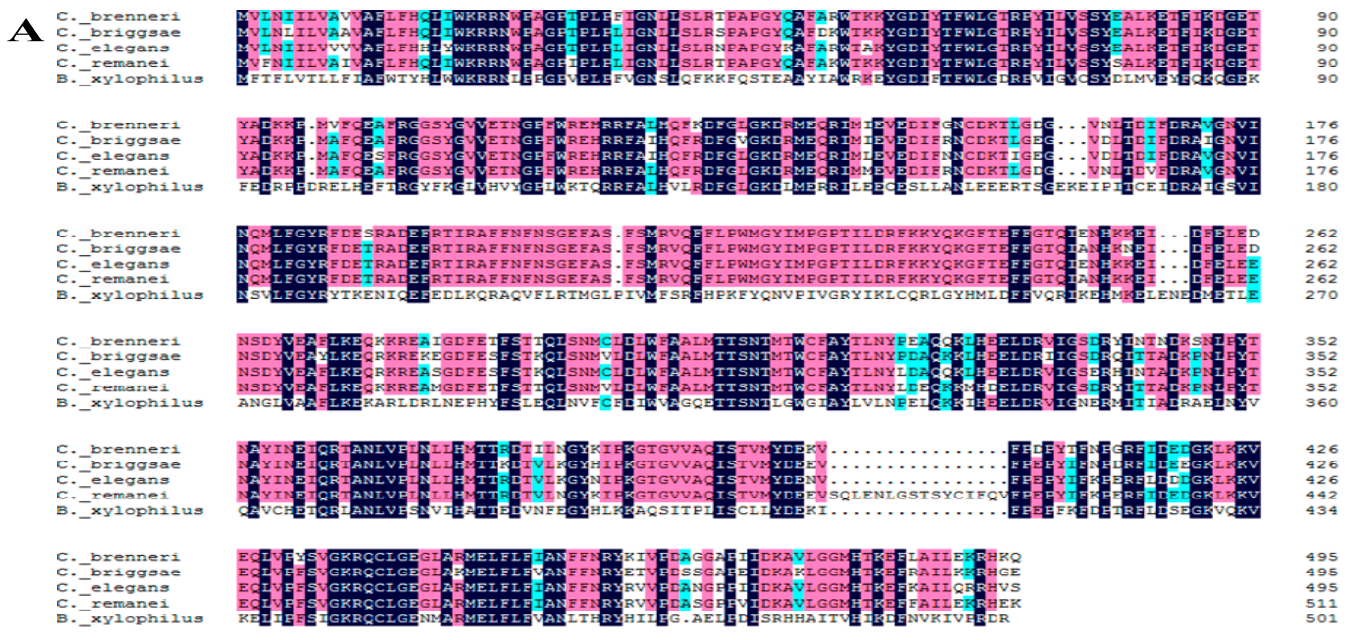

Figure 2. Cont. 


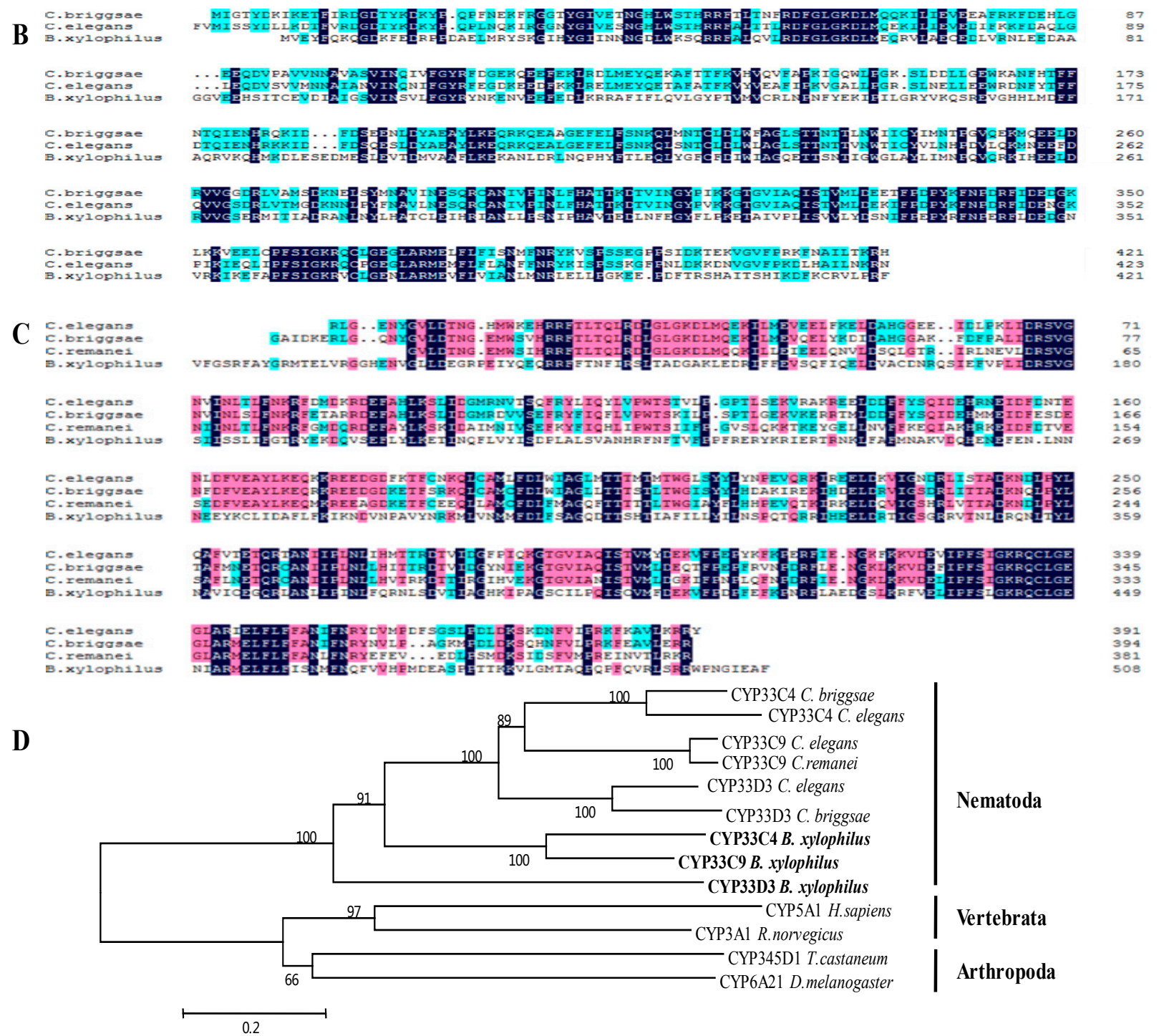

Figure 2. Multiple alignments of predicted BxCYP33C9, BxCYP33C4 and BxCYP33D3 of B. xylophilus with other organism CYP proteins. (A) Comparison for protein homolo-gogy of CYP33C9 from B. xylophilus, C. brenneri, C. elegans, C. remanei and C. briggsae; (B) Comparison for protein homologogy of CYP33C4 from B. xylophilus, C. elegans and C. briggsae; (C) Comparison for protein homologogy of CYP33D3 from B. xylophilus, C. elegans, C. remanei and C. briggsae; Note: Letters in black boxes, red boxes, and blue boxes indicate invariant amino acid residues, highly conserved amino acid residues, and moderately conserved amino acid residues, respectively, among the CYP proteins; (D) Analysis on phylogenetic trees of the deduced CYP33C9, CYP33C4 and CYP33D3 protein sequences with other organism CYP proteins. The full-length CYP proteins sequences utilized in this analysis were as follows: NP_507679.2 (Caenorhabditis elegans CYP33D3), XP_002645739.1 (C. briggsae CYP33D3), CAP22529.1 (C. briggsae CYP33C4), NP_503612.1 (C. elegans CYP33C4), NP_503846.1 (C. elegans CYP33C9), XP_003115467.1 (C. remanei CYP33C9), P24557.3 (Homo sapiens CYP5A1), EFA05713. 1 (Tribolium castaneum CYP345D1), NP_037237.2 (Rattus norvegicus CYP3A1), AAF58186.1 (Drosophila melanogaster CYP6A21). KM973210 (B. xylophilus CYP33C9), KM973211 (B. xylophilus CYP33C4), KM973212 (B. xylophilus CYP33D3). 


\subsection{Characteristics of the Three Predicted Proteins}

The characteristics of the putative proteins were analyzed with biological information methods. The protein molecular formula of BxCYP33C9, BxCYP33C4 and BxCYP33D3 were $\mathrm{C}_{2695} \mathrm{H}_{4146} \mathrm{~N}_{714} \mathrm{O}_{732} \mathrm{~S}_{19}, \mathrm{C}_{2205} \mathrm{H}_{3430} \mathrm{~N}_{598} \mathrm{O}_{633} \mathrm{~S}_{19}$, and $\mathrm{C}_{2676} \mathrm{H}_{4136} \mathrm{~N}_{714} \mathrm{O}_{739} \mathrm{~S}_{20}$, respectively. Their predicted isoelectric points were $6.65,5.51$, and 7.58 , respectively. The molecular masses were predicted to be 58, 49 and $58 \mathrm{kDa}$, respectively, according to the rule that P450s molecular weight for 46-60 $\mathrm{kDa}$. Relatively high quantities of amino acids of BxCYP33C9 were leucine (Leu) (55, 11.0\%), glutamate (Glu) (45, 9.0\%), and phenylalanine (Phe) (36, 7.2\%). Relatively high quantities of amino acids of BxCYP33C4 were leucine (Leu) (44, 10.4\%), glutamate (Glu) (40, 9.5\%), and arginine (Arg) (30, 7.1\%). Relatively high quantities of amino acids of BxCYP33D3 were leucine (Leu) (50, 9.8\%), phenylalanine (Phe) (45, 8.8\%), Isoleucine (Ile) (39, 7.7\%). Results of SignalP 4.1 software showed that there was no signal peptide sequence, while TMHMM server 2.0 showed that there was a transmembrane region between 1-21 amino acids in BxCYP33D3, illustrating that BxCYP33D3 was a membrane binding protein. Unlike BxCYP33D3, results showed that there was no transmembrane structure or signal peptide sequence in the deduced BxCYP33C9 and BxCYP33C4 sequences, indicating that these two proteins of B. xylophilus might locate in the cell matrix or organelles since they are hydrophilic. They are likely to exist in a soluble form in organisms.

\subsection{Detection of RNAi Efficiency}

The size of the three dsRNA sequences which contain conservative regions of CYPs, dsCYP33C9, dsCYP33C4 and dsCYP33D3, were 641, 428 and $483 \mathrm{bp}$, respectively. qPCR was used to determine the effect of RNAi on the BxCYP33C9, BxCYP33C4 and BxCYP33D3 mRNA levels. The Actin gene of $B$. xylophilus was utilized as an internal control. Soaking nematodes in dsCYP33C9, dsCYP33C4 and dsCYP33D3 solution resulted in a significant decrease in $B x C Y P 33 C 9, B x C Y P 33 C 4$ and $B x C Y P 33 D 3$ gene expressions compared to the nematodes soaked in $\mathrm{ddH}_{2} \mathrm{O}$ (control) (Figure 3). Taking the mRNA expression level of the control as 1.00, the mean expression level ofdsCYP33C9, dsCYP33C4 and dsCYP33D3 treated samples were $0.05,0.14$ and 0.05 , respectively. These results indicated that $B x C Y P 33 C 9, B x C Y P 33 C 4$ and $B x C Y P 33 D 3$ of B. xylophilus had been inhibited by RNAi successfully.

\subsection{Vitality and Dispersal Ability of B. xylophilus after RNAi}

The biological characteristic of B. xylophilus after RNAi was demonstrated and analyzed. MostdsRNA-soaked B. xylophilus in the Figure 4A were relatively clear compared to the nematodes soaked in $\mathrm{ddH}_{2} \mathrm{O}$ (controls), especially for B. xylophilus soaked in dsCYP33C9 and dsCYP33C4, which means they were moving slower than the control. In addition, the thrashing rate of $B$. xylophilus soaked in $\mathrm{ddH}_{2} \mathrm{O}$, dsCYP33D3, dsCYP33C4, dsCYP33C4 were 47, 28, 7, 6 thrashes/min, respectively (Figure 4B). The results indicated that the vitality of PWN was reduced significantly after soaking in dsRNA solutions, especially for B. xylophilus soaked in dsCYP33C9 and dsCYP33C4, compared to the nematodes soaked in $\mathrm{ddH}_{2} \mathrm{O}$. Moreover, results showed that it took a longer time for dsRNA-treated pine wood nematodes to pass through the branch of an equal length of $P$. thunbergii (Table 1), 
especially for B. xylophilus soaked in dsCYP33C9. Taken together, these results indicated that some functions related to the vitality and dispersal ability of $B$. xylophilus were likely to be influenced while the genes encoding cytochrome P450 were silenced by RNAi.

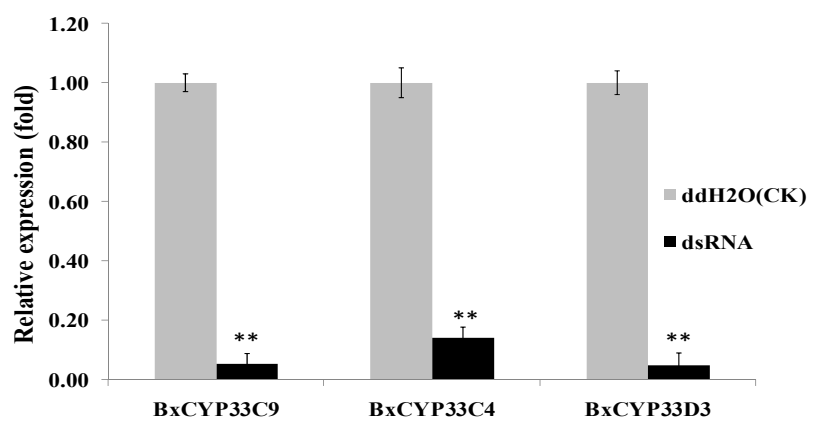

Figure 3. Quantitative real-time RT-PCR analysis of the RNAi efficiency in B. xylophilus after treatment with dsCYP33C9, dsCYP33C4 and dsCYP33D3. B. xylophilus soaked in $\mathrm{ddH}_{2} \mathrm{O}$ was used as control. Data represent mean values $\pm \mathrm{SD}$ from three independent experiments. Bars show standard deviations of the mean. Asterisks on top of the bars indicate statistically significant differences $(* * p<0.01$, Student's $t$-test) was found between the dsRNA-treated (dsCYP33C9, dsCYP33C4 and dsCYP33D3) and control.

A
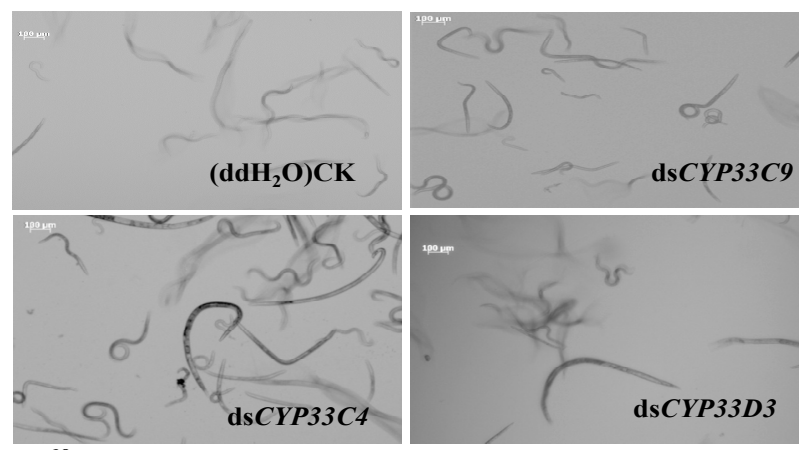

B

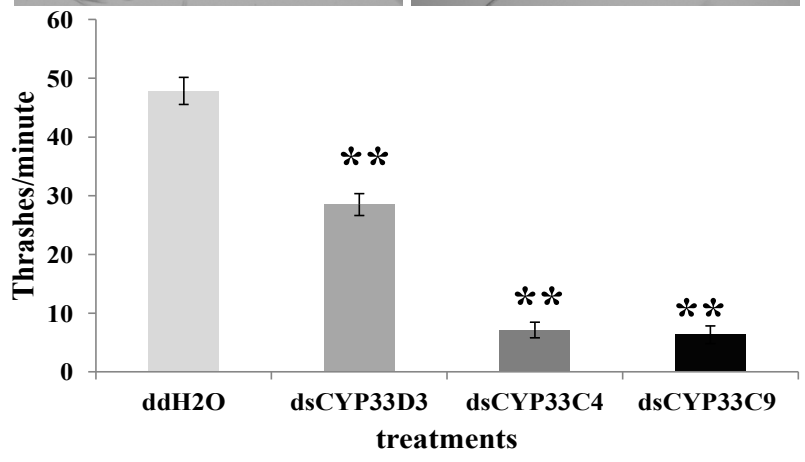

Figure 4. Effect of RNAi to vitality of B. xylophilus. (A) Morphology and movement of B. xylophlilus after soaking in dsRNA (dsCYP33C9, dsCYP33C4 and dsCYP33D3) for $48 \mathrm{~h}$. All the pictures were taken under normal conditions (in proper focus). Scale bars $=100 \mu \mathrm{m}$; (B) Thrashing rate of B. xylophilus after soaking in dsRNA. B. xylophilus soaked in $\mathrm{ddH}_{2} \mathrm{O}$ were used as control. Data represent mean values $\pm \mathrm{SD}$ from three independent experiments. Bars show standard deviations of the mean. Asterisks on top of the bars indicate statistical differences $(* * p<0.01$, Student's $t$-test) were found between the dsRNA-treated (dsCYP33C9, dsCYP33C4 and dsCYP33D3) nematodes and controls. 
Table 1. Effect of RNAi to the dispersal ability of B. xylophilus.

\begin{tabular}{ccc}
\hline Treatments & Detected Time (h) & Number of Nematodes \\
\hline $\mathrm{ddH}_{2} \mathrm{O}$ & 12 & $8.3 \pm 2.5$ \\
$\mathrm{ds} C Y P 33 D 3$ & 24 & $2.7 \pm 1.1$ \\
$\mathrm{ds} C Y P 33 C 4$ & 96 & $2.3 \pm 1.5$ \\
$\mathrm{ds} C Y P 33 C 9$ & 144 & $3.7 \pm 1.5$ \\
\hline
\end{tabular}

\subsection{Reproduction and Pathogenicity of B. xylophilus after RNAi}

The effect of RNAi on B. xylophilus reproduction was performed on PDA plates inoculated with $B$. cinerea. The pine wood nematodes soaked in dsRNA solution showed significantly reduced population compared with the controls (nematodes soaked in $\mathrm{ddH}_{2} \mathrm{O}$ ) and this result was confirmed from the B. xylophilus feeding situations of different treatments at different periods (Figure 5A). After 9 days at $25{ }^{\circ} \mathrm{C}$, the reproduction rates of nematodes soaked in dsCYP33D3, dsCYP33C4, dsCYP33C9 and $\mathrm{ddH}_{2} \mathrm{O}$ were 111-, 322-, 483- and 650-fold, respectively (Figure 5B). These results indicated that feeding and reproduction of $B$. xylophilus were significantly influenced by the RNAi treatment, especially for nematodes with the dsCYP33D3-treatment. On the other hand, after the 2-year-old P. massoniana seedlings were inoculated with dsRNA-treated B. xylophilus, wilting first appeared in the seedlings inoculated with nematodes soaked in $\mathrm{ddH}_{2} \mathrm{O}$ and the wilting rate was $83.3 \%$. Four days later, the seedlings inoculated with nematodes soaked in dsCYP33D3 solution began to wilt and the wilting rate was $100 \%$. Another four days later, the seedlings inoculated with nematodes soaked in dsCYP33C4 solution began to wilt and the wilting rate was $83.3 \%$. The seedlings inoculated with nematodes soaked in dsCYP33C9 solution were the last ones to wilt and the wilting rate was $83.3 \%$ (Figure 6). The results indicated that the silencing of $B x C Y P 33 C 9, B x C Y P 33 C 4$ and $B x C Y P 33 D 3$ genes of B. xylophilus resulted in a loss of pathogenicity at some level.

A

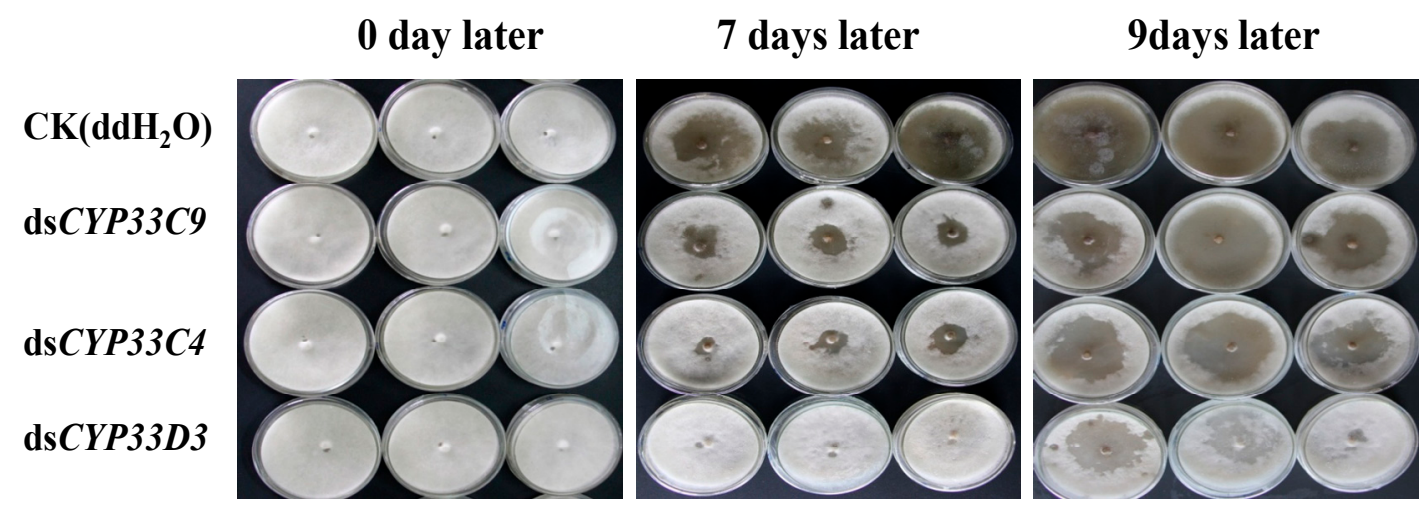

Figure 5. Cont. 


\section{B}

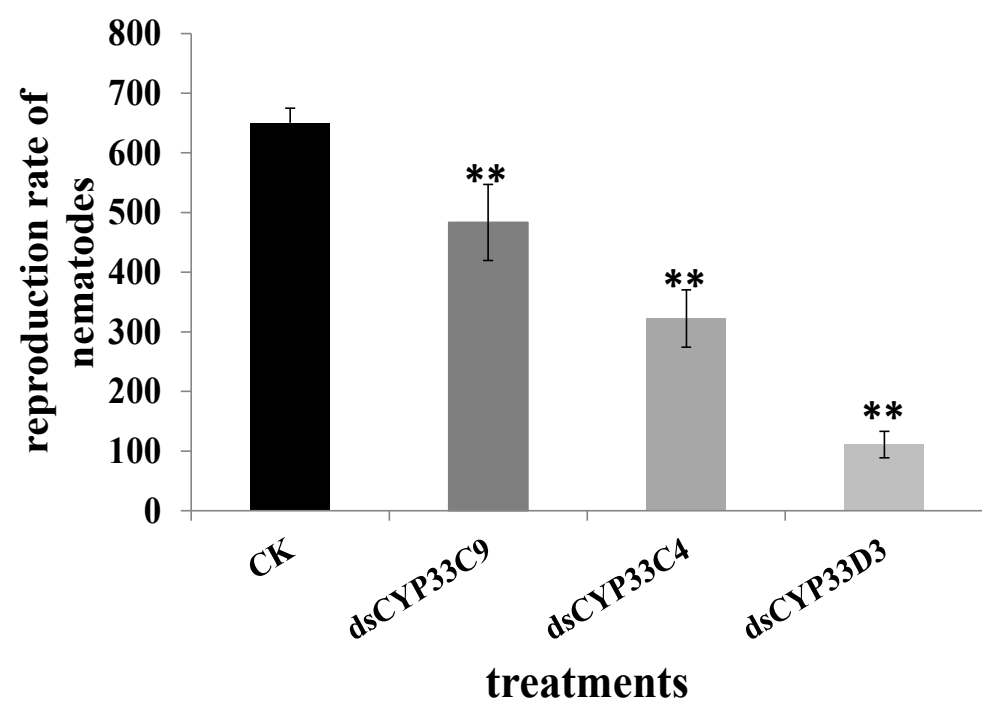

Figure 5. Effect of RNAi on reproduction of B. xylophilus. (A) RNAi-treated B. xylophilus after cultivation with $B$. cinerea; (B) Reproduction rate of $B$. xylophilus washed from PDA plate of $B$. cinerea with and without dsRNA (dsCYP33C9, dsCYP33C4 and dsCYP33D3) treatment. B. xylophilus soaked in $\mathrm{dd}_{2} \mathrm{O}$ were used as controls. Data represent mean values \pm SD from three independent experiments. Bars show standard deviations of the mean. Asterisks on top of the bars indicate statistically significant differences $(* * p<0.01$, Student's $t$-test) was found between the dsRNA-treated (dsCYP33C9, dsCYP33C4 and dsCYP33D3) nematodes and controls.

0 day later

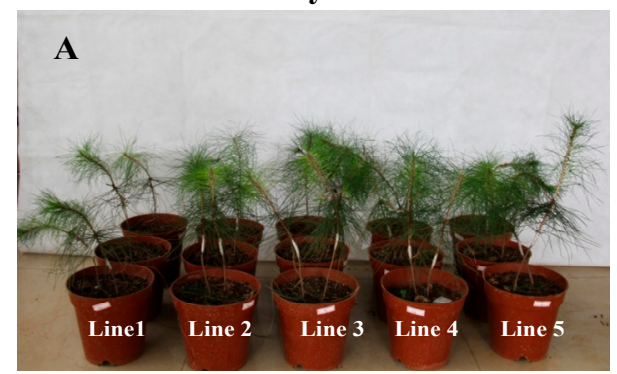

12 days later

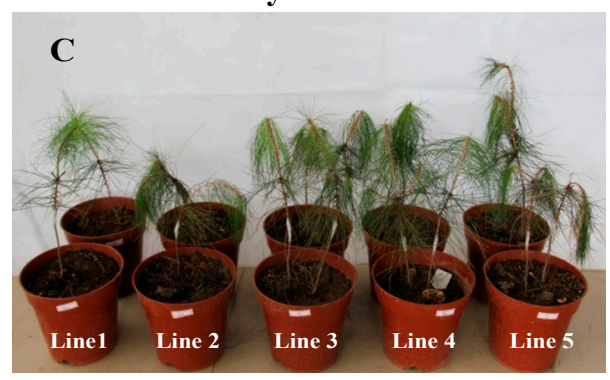

9 days later

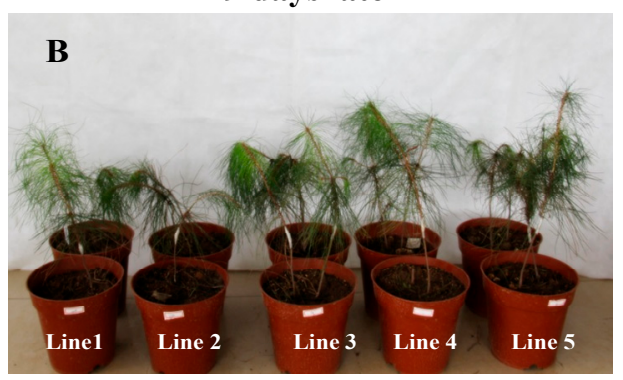

16 days later

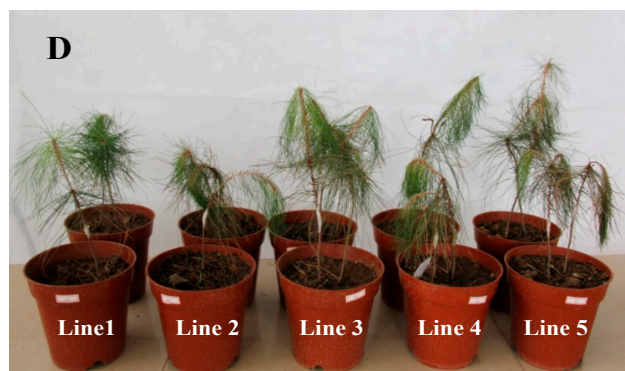

Figure 6. Symptoms in P. massoniana seedlings 0 (A), 9 (B), 12 (C) and 16 (D) days after inoculation with nematodes soaked in dsCYP33C9 (line 3), dsCYP33C4 (line 4) and dsCYP33D3 (line 5) solution and $\mathrm{ddH}_{2} \mathrm{O}$ (line 2). P. massoniana seedlings inoculated with $\mathrm{ddH}_{2} \mathrm{O}$ alone were considered as controls (line 1). 


\subsection{Susceptibility of B. xylophilus to Pesticides after RNAi}

To further explore possible insecticide detoxification function of the three cytochrome P450 genes in B. xylophilus, nematodes with dsRNA-treatment were soaked in abamectin and emamectin solution, respectively. Observation of $B$. xylophilus under an optical microscope found that the vitality of B. xylophilus with the cytochrome P450 dsRNA treatments soaked in pesticides was significantly diminished compared to those with $\mathrm{ddH}_{2} \mathrm{O}$ treatment (Figure 7A). Our results showed that the mortalities of the nematodes treated with dsCYP33C9, dsCYP33C4 and dsCYP33D3 were 13.7\%, $31.5 \%$ and $20.5 \%$, respectively, higher than the controls when abamectin was used in our bioassays (Figure 7B). Furthermore, the mortalities of B. xylophilus treated with dsCYP33C9, dsCYP33C4 and dsCYP33D3 were $10.4 \%, 37.6 \%$ and $26 \%$, respectively, higher than the controls when emamectin was used in our bioassays (Figure 7B). These results indicated that the three cytochrome P450 genes may be involved in the resistance of B. xylophilus to pesticides.

\subsection{Discussion}

In this article, using RACE technology, we cloned and analyzed the full-length cDNA of three cytochrome P450 genes, $B x C Y P 33 C 9, B x C Y P 33 C 4$ and $B x C Y P 33 D 3$, from $B$. xylophilus, which had never been reported. Sequence analysis showed that the deduced amino acid sequences of BxCYP33C9, BxCYP33C4 and BxCYP33D3 exhibited a relatively high level of identity with the CYP33C9, CYP33C4 and CYP33D3 proteins of nematodes of Caenorhabditis. In addition, RNAi technology was used to demonstrate the functions of the three cytochrome P450 genes. The results indicated that the three genes were associated with the vitality, dispersal ability, reproduction, pathogenicity and pesticide metabolism of B. xylophilus. This is the first example of three functional cytochrome P450s from B. xylophilus.

$\mathbf{A}$

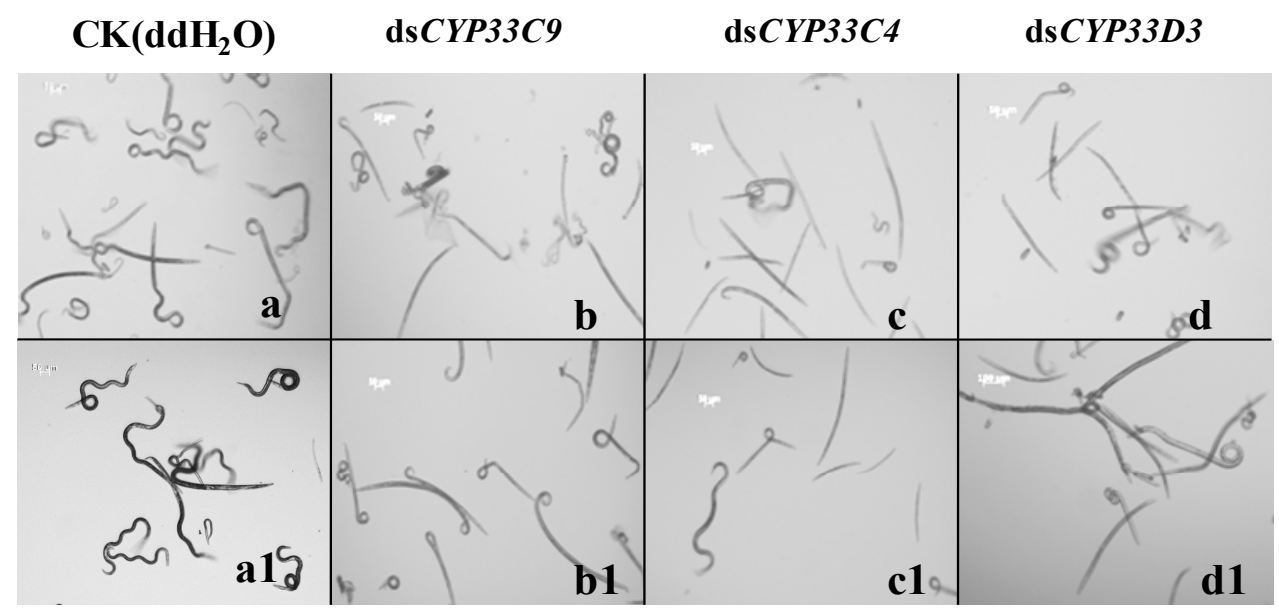

Figurg 7. Cont. 


\section{B}

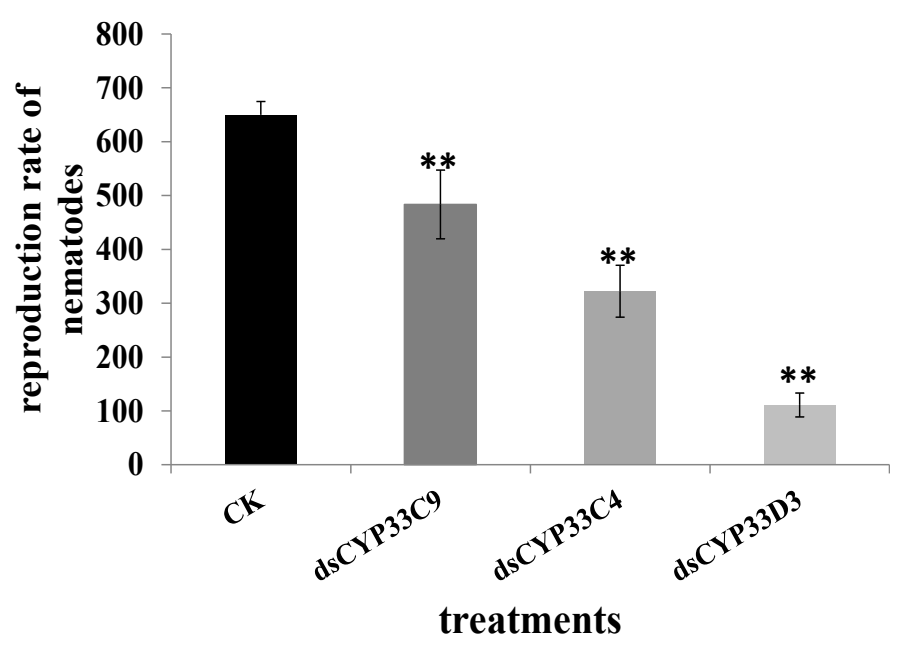

Figure 7. Analysis of susceptibility of $B$. xylophilus to to commonly used pesticides. (A) Microscopy analysis of morphology and locomotion of B. xylophlilus after soaking in two commonly used pesticides. B. xylophilus without RNAi treatment soaked in abamectin (a) and emamectin (a1) solution were conducted as controls. The treatments were dsCYP33C9-treated B. xylophilus soaked in abamectin (b) and emamectin (b1) solution, dsCYP33C4-treated B. xylophilus soaked in abamectin (c) and emamectin (c1) solution, dsCYP33D3-treated B. xylophilus soaked in abamectin (d) and emamectin (d1) solution. Scale bars $=100 \mu \mathrm{m}$; (B) Increases in mortalities of B. xylophilus with RNAi after soaking in pesticides. B. xylophilus without RNAi treatment with a pesticide and those injected with $\mathrm{ddH}_{2} \mathrm{O}$ were considered as controls. Data represent mean values \pm SD from three independent experiments. Bars show standard errors of the mean. Asterisks on top of the bars indicate statistical significance $(* * p<0.01$, Student's $t$-test) of differences between the dsRNA-treated and controls.

To date, there are three hypotheses concerning the pine wood pathogenic mechanism: The enzyme hypothesis, the hollowing-out hypothesis, and the toxins hypothesis [19,20]. Since the plant cell wall is the primary barrier that pine wood nematodes must penetrate [21], cell wall-degrading enzymes such as cellulase [8], pectatelyases [9], and hemicellulose have always been proposed to determine the pathogenicity of pine wood nematodes. Recently, a number of studies have focused on the pathogenesis related genes of $B$. xylophilus, especially the cellulase and pectatelyase genes that are expressed in the esophageal glands of nematodes. Both cellulase and pectatelyase proteins were secreted through the nematode stylet into plant tissues and participated in the weakening of the cell walls, facilitating feeding, penetration and migration of nematodes in pine tissues [8]. Furthermore, many other proteins, such as expansin [22,23], venom-allergen proteins (VAP) [24], heat shock proteins (Hsp) [25,26], and small heat shock proteins (sHSPs) [27,28] were identified to contribute to cell wall degradation, resistance to adverse environment, migration, growth and the development process of B. xylophilus. In the present study, three cytochrome $\mathrm{P} 450$ genes were cloned from the pine wood nematode and function analysis showed that the silencing of three cytochrome P450 genes reduced dispersal ability of $B$. xylophilus in the host pine trees and its reproduction on $B$. cinerea. These results indicated that besides the cell wall-degrading enzymes, other enzymes might also play 
important roles in the pathogenic process of B. xylophilus. Cytochrome P450, a microsomal mixed function oxidase, plays important roles in metabolizing a wide range of endogenous and exogenous compounds. An important feature of cytochrome P450 enzymes is inducibility, which means that both enzymes' activity level and gene transcription level of cytochrome P450 were significantly increased when insects or plants were exposed to a pesticide or other exogenous material [29,30]. A series of researches have shown that the presence of plant secondary metabolites and chemical compounds in the environment could induce the expression of CYP450 genes [31-33]. C. elegans CYP450s have been confirmed to catalyze a series of exogenous and endogenous substrates under different growth conditions [14]. Furthermore, it was proved that the cytochrome P450s of insects, such as Helicover armigera (Hübner), Locusta migratoria, Tribolium castaneum (Herbst), play an important role in detoxification of pesticides [15-17]. The chemical nature of cytochrome P450-mediated insect resistance is that the cytochrome P450 enzyme system can effectively catalyze the degradation and metabolism of pesticides, which result in the failure of acting on the target site. Our results indicated that this phenomenon may also occur in B. xylophilus. In our study, the mortalities of B. xylophilus with RNAi treatment were markedly increased when exposed to two kinds of commonly used nematicides, abamectin and emamectin, which indicated that the three cytochrome P450 genes may also play a pesticide detoxification role in B. xylophilus and thus improve B. xylophilus' resistance to pesticide. This is the first study of the endogenous substrates of cytochrome P450 in B. xylophilus. In addition, in order to combat the invasion by pine wood nematodes, numerous secondary metabolites are generated in pine trees, such as cyclic aromatics and terpenoids [34]. At the same time, B. xylophilus must also mobilize reciprocal defensive reactions to avoid damage from the complex compounds. In the present study, the deletion of the $B x C Y P 33 C 9, B x C Y P 33 C 4$ and $B x C Y P 33 D 3$ genes of $B$. xylophilus resulted in a loss of pathogenicity indicating that CYP450s may enhance the pathogenicity role of $B$. xylophilus through the mobilization of $P$. massoniana secondary metabolites or the production of toxic metabolites that damage the pine trees. However, the specific substrates of CYP450s in B. xylophilus need to be further investigated.

Overall, this study focused on the molecular characterization and functional analysis by RNAi of three cytochrome P450 genes from B. xylophilus. These discoveries would provide a better understanding of the molecular mechanism of pathogenesis of B. xylophilus and contribute to management of pine wood nematodes in the future.

\section{Experimental Section}

\subsection{Materials}

The highly virulent AMA3 strain of B. xylophilus used in this study was isolated from wood chips of infested Pinus thunbergii Parl from Maanshan, Anhui, China, which was maintained in the forest pathology laboratory of Nanjing Forestry University, Nanjing, China. The Botrytis cinerea strain was also provided by our laboratory. Two-year-old $P$. massoniana seedings and five-year-old $P$. thunbergii used in this study were grown in the greenhouse $\left(32^{\circ} 077^{\prime} \mathrm{N}, 118^{\circ} 808^{\prime} \mathrm{E}\right)$ at $30^{\circ} \mathrm{C}$ during the daytime and $25{ }^{\circ} \mathrm{C}$ at night, with $70 \%$ relative humidity. Two commonly used pesticides, abamectin and emamectin, were purchased from Hebei Veyong Bio-Chemical Pesticide Co., Ltd. (Shijiazhuang, China). 


\subsection{Collection of B. xylophilus}

Isolate of $B$. xylophilus was grown in $B$. cinerea culture on potato dextrose agar (PDA) plates at $25^{\circ} \mathrm{C}$ for 5-7 days. Baermann funnel method was used to separate B. xylophilus from PDA plates. B. xylophilus was collected by centrifugation at $3500 \mathrm{rpm}$ for $3 \mathrm{~min}$ and washed three times with distilled water. The nematodes were immediately frozen in liquid nitrogen and eventually stored at $-80^{\circ} \mathrm{C}$ in a $1.5 \mathrm{~mL}$ centrifuge tube for subsequent RNA extraction.

\subsection{RNA Extraction of B. xylophilus}

The collected nematodes were ground into powder in a mortar after joining the liquid nitrogen. Total RNA of nematodes was extracted using an optimized Trizol method with Trizol reagent (Invitrogen, Waltham, MA, USA). The RNA was measured by ultraviolet absorbance at A260/280 (Eppendorff AG 22331, Hamburg, Germany) and examined by electrophoresis on a 1\% agarose gel.

\subsection{Full-Length cDNA Cloning of P450s from B. xylophilus}

The full-length $B x C Y P 33 C 4$ and BxCYP33D3 cDNA were obtained using the 3'-Full RACE Core Set with PrimeScript ${ }^{\mathrm{TM}}$ RTase kit (TaKaRa Biotechnology, Dalian, China) and the full-length cDNA of BxCYP33C9 was obtained using 5'-Full RACE Kit with TAP (TaKaRa Biotechnology, Dalian, China). Gene-specific primers GSP1 (for BxCYP33C4) and GSP2 (for BxCYP33D3), GSP3 (for $B x C Y P 33 C 9$ first round of PCR) and GSP4 (for BxCYP33C9 second round of PCR) (Table 2) were, respectively, designed for 3 ' and 5' RACE amplification based on three partially known sequences of $B x C Y P 33 C 4, B x C Y P 33 D 3$ and $B x C Y P 33 C 9$ which were obtained from the DNA microarrays results [18]. The amplification profiles were all as follows: A cycle at $94{ }^{\circ} \mathrm{C}$ for $3 \mathrm{~min}, 30$ cycles at $94{ }^{\circ} \mathrm{C}$ for $30 \mathrm{~s}, 55{ }^{\circ} \mathrm{C}$ for $30 \mathrm{~s}, 72{ }^{\circ} \mathrm{C}$ for $2 \mathrm{~min}$, and $72{ }^{\circ} \mathrm{C}$ for $10 \mathrm{~min}$. The resulting nested PCR products were purified and recycled according to the Gel Extraction Kit (Axygen, Hangzhou, China) manufacturer's instructions. Subsequently, the amplified PCR products were cloned into the pEASY-T1 vector (TransGen Biotech, Beijing, China), and transformed into Escherichia coli Trans1-T1 competent cells (TransGen Biotech, Beijing, China) and then plated on a selective medium. A single colony of the transformants was inoculated and cultured at $37^{\circ} \mathrm{C}$ in $\mathrm{LB}$ medium containing ampicillin $(50 \mu \mathrm{g} / \mathrm{mL})$ with shaking for $4 \mathrm{~h}$. The fresh bacterial suspension liquid was sequenced at Nanjing Genscript sequencing company (Nanjing, China) after PCR detection with primers M13F (-47) and M13R (-48) (Table 1).

\subsection{Bioinformatic Analysis}

Amino acid sequences of homologous BxCYP33C9, BxCYP33C4 and BxCYP33D3 proteins from other organisms were obtained from NCBI using Blastp (available online: http://blast.ncbi.nlm. nih.gov/Blast.cgi). Multiple sequence alignment of deduced protein sequences was carried out with DNAMAN software and phylogenetic analysis of these two P450 proteins was carried out with MEGA 6.0 software using the neighbor-joining (NJ) method. The characteristics of predicted BxCYP33C9, BxCYP33C4 and BxCYP33D3 proteins such as amino acids composition prediction and protein molecular weight and isoelectric point calculation (available online: http://cn.expasy.org/tools/ 
protparam.html), signal peptide prediction (available online: http://genome.cbs.dtu.dk/services/SignalP), prediction of transmembrane helices in proteins (available online: http://www.cbs.dtu.dk/services/ TMHMM/) were analyzed on the bioinformatics website.

Table 2. PCR primers used in the present study.

\begin{tabular}{|c|c|}
\hline Name of Primer & Sequence (5'-3') \\
\hline \multicolumn{2}{|r|}{ cDNA Cloning of three cytochrome P450 genes } \\
\hline 3'RACE outer primer & TACCGTCGTTCCACTAGTGATTT \\
\hline GSP1 & TTCGCCCGAACAAGCGTATA \\
\hline GSP2 & AATGTTGGACTGCTGGATGA \\
\hline 5'RACE outer primer & CATGGCTACATGCTGACAGCCTA \\
\hline GSP3 & TGTGATAGCGATGAGTGA \\
\hline 5'RACE inner primer & CGCGGATCCACAGCCTACTGATGATCAGTCGATG \\
\hline GSP4 & TTGAAAGGCTCGGGAAAT \\
\hline $\mathrm{M} 13 \mathrm{~F}(-47)$ & CGCCAGGGTTTTCCCAGTCACGAC \\
\hline $\operatorname{M13R}(-48)$ & AGCGGATAACAATTTCACACAGGA \\
\hline \multicolumn{2}{|r|}{ Preparation of template DNA for dsRNA } \\
\hline$B x \mathrm{C} 4 \mathrm{~T} 7 \mathrm{~F}$ & TAATACGACTCACTATAGGGTTGGGAGTGAACGGATGA \\
\hline$B x \mathrm{C} 4 \mathrm{R}$ & GATCGCATGACTTCTTGTA \\
\hline$B x \mathrm{C} 4 \mathrm{~F}$ & TTGGGAGTGAACGGATGA \\
\hline BxC4T7R & TAATACGACTCACTATAGGGGATCGCATGACTTCTTGTA \\
\hline$B x \mathrm{C} 9 \mathrm{~T} 7 \mathrm{~F}$ & TAATACGACTCACTATAGGGGCAGCTATGATTGATGGT \\
\hline$B x \mathrm{C} 9 \mathrm{R}$ & CAATGAGAAGTAATGTGGC \\
\hline$B x \mathrm{C} 9 \mathrm{~F}$ & GCAGCTATGATTGATGGT \\
\hline BxC9T7R & TAATACGACTCACTATAGGGCAATGAGAAGTAATGTGGC \\
\hline$B x \mathrm{D} 3 \mathrm{~T} 7 \mathrm{~F}$ & TAATACGACTCACTATAGGGGCCCGAGATTTACCAAGA \\
\hline$B x \mathrm{D} 3 \mathrm{R}$ & AACGCATCAATCAGACACTT \\
\hline$B x \mathrm{D} 3 \mathrm{~F}$ & GCCCGAGATTTACCAAGA \\
\hline$B x \mathrm{D} 3 \mathrm{~T} 7 \mathrm{R}$ & TAATACGACTCACTATAGGGAACGCATCAATCAGACACTT \\
\hline \multicolumn{2}{|r|}{ Real time PCR } \\
\hline qC9F1 & GCGGTTTGCCATGAGACT \\
\hline qC9R1 & AAACGGGTGGGATCGAAT \\
\hline $\mathrm{qC} 4 \mathrm{~F} 1$ & AAGATCGACCGCCAGATG \\
\hline qC4R1 & CACCTCCAGCTGCATCCT \\
\hline qD3F1 & CTGATGGGGCAAAGTTGG \\
\hline qD3R1 & GCGGGTCCGAAATGTAGA \\
\hline Actin F & GCAACACGGAGTTCGTTGTAGA \\
\hline Actin $\mathrm{R}$ & GTATCGTCACCAACTGGGATGA \\
\hline
\end{tabular}

The $\mathrm{T} 7$ promoter sequences were underlined.

\subsection{RNA Interference (RNAi)}

RNA interference (RNAi) was first described in Caenorhabditis elegans for analysis of gene function [35]. Later, RNAi was developed as an effective tool used in plants and animals for gene function study and genetic manipulation [36-38]. In this study, RNAi technology was used to assess the functions of the three cytochrome P450 genes in B. xylophilus. Recombinant plasmids were 
extracted from the bacteria liquid which had been shook at $200 \mathrm{rpm}$ for $24 \mathrm{~h}$ at $37^{\circ} \mathrm{C}$ according to the AxyPrep $^{\text {TM }}$ Plasmid Mini prep Kit manufacturer's protocol (Axygen, Hangzhou, China). The DNA templates used for synthesizing double-stranded RNA (dsRNA) were amplified with the primers in Table 2 and then dsRNA was synthesized using the MEGscript RNAi Kit (Ambion Inc., Austin, TX, USA). The RNAi soaking method used in this study was performed according to a previous report [39]. Approximately 3000 individuals (a mix of juveniles and adults) of freshly cultured B. xylophilus were soaked in $50 \mu \mathrm{L}$ dsRNA $(800 \mathrm{ng} / \mu \mathrm{L})$ after being washed with distilled water for 3 times at $3500 \mathrm{rpm}$ for $3 \mathrm{~min}$ and then incubated at $180 \mathrm{rpm}$ for $48 \mathrm{~h}$ at $20^{\circ} \mathrm{C}$. The same number of

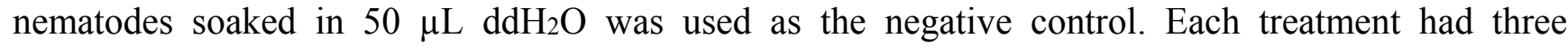
replicates. Samples from each treatment were washed thoroughly with $\mathrm{ddH}_{2} \mathrm{O}$ for several times after soaking and then used for additional experiments.

\subsection{Quantitative Real-Time RT-PCR}

In order to verify that $B x C Y P 33 C 9, B x C Y P 33 C 4$ and $B x C Y P 33 D 3$ of B. xylophilus had been knocked down by RNAi successfully, quantitative real-time PCR (qPCR) was used to detect interference efficacy. Total RNA extractions from B. xylophilus after RNAi were carried out as described previously in our study. The first-strand cDNA was then synthesized using a cDNA synthesis Kit (TransGen Biotech, Beijing, China) with $2 \mu \mathrm{g}$ of total RNA according to the manufacturer's instructions. The synthesized cDNA was stored at $-20{ }^{\circ} \mathrm{C}$ after being measured by ultraviolet absorbance at A260/280 (Eppendorff AG 22331, Hamburg, Germany). qPCR was then carried out using TransStart Green qPCR Super Mix (TransGen Biotech, Beijing, China) and ABI Prism 7500 (Applied Biosystems, Foster City, CA, USA), with the primers listed in Table 2. The thermal profile used was: $94{ }^{\circ} \mathrm{C}$ for $30 \mathrm{~s}, 40$ cycles of $94{ }^{\circ} \mathrm{C}$ for $5 \mathrm{~s}$, and $60{ }^{\circ} \mathrm{C}$ for $34 \mathrm{~s}$. Actin gene of B. xylophilus was utilized as internal control. Relative expression levels were determined using the ABI Prism 7500 software and $2^{-\Delta \Delta C t}$ method. qPCR was carried out with three biological replicates and three technical replicates.

\subsection{Analysis of Vitality and Dispersal Ability of B. xylophilus after RNAi}

The vitality of B. xylophilus was examined and photographed using a Zeiss Axio Image M2 microscope (Zeiss MicroImaging GmbH, Oberkochen, Germany). About 100 nematodes from each treatment were observed. If moving too fast, B. xylophilus cannot be photographed clearly, so the sharpness of nematodes in the photographs reflected swing speed of B. xylophilus to some extent. In addition, thrashing rate was conducted for evaluating the vitality of B. xylophilus according to Tsalik and Hobert [40]. After a 2-min recovery period, thrashes were counted for $1 \mathrm{~min}$. A thrash of B. xylophilus was defined as the head from one direction to another direction, and then same action was repeated again. The detection of B. xylophilus' dispersal ability was performed according to a previous method [41]. First, a rubber tubing (about $3 \mathrm{~cm}$ in height, $1 \mathrm{~cm}$ in diameter) was upended on one end of a fresh $P$. thunbergii branch (about $5 \mathrm{~cm}$ in length, $1 \mathrm{~cm}$ in diameter), and the other end of the branch was then put into a small dish with $1 \mathrm{~mL}$ sterile water. Then a piece of sterile absorbent cotton was put into the rubber tubing. All of these were put into a bottle in the end. Subsequently, $200 \mu \mathrm{L}$ of mixed suspension containing 150 nematodes was dropped on the absorbent cotton. 
The water in the dish was observed with optical microscopy during a 6-h interval and the number of nematodes and the time of its first appearance were recorded during the time. Each treatment in this experiment has three replicates and the experiment was repeated twice.

\subsection{Analysis of Reproduction and Pathogenicity of B. xylophilus after RNAi}

Fifteen pairs of female and male $B$. xylophilus with RNAi treatment were picked and cultured on a PDA plate with $B$. cinerea at $25^{\circ} \mathrm{C}$ for 9 days. The feeding situation of $B$. xylophilus was observed and photographed periodically. Subsequently, the nematodes were washed off the plates and counted with an optical microscope. In order to determine the pathogenicity of B. xylophilus after RNAi, 1000 nematodes were injected into each 2-year-old $P$. massoniana seedling, according to a previous method [42]. B. xylophilus soaked in $\mathrm{ddH}_{2} \mathrm{O}$ without dsRNA and $\mathrm{ddH}_{2} \mathrm{O}$ alone were utilized as controls. Photographs were taken regularly to record the seedlings' infection state. Each control group in this experiment has six individuals.

\subsection{Analysis of Susceptibility of B. xylophilus to Pesticides after RNAi}

At present, a large number of studies on the cytochrome P450 genes were focused on its detoxification function to pesticides, especially on insects such as Helicover armigera (Hübner), Locusta migratoria, Tribolium castaneum (Herbst) [15-17]. To further explore possible insecticide detoxification roles of the three cytochrome P450 genes in B. xylophilus, two kinds of commonly used nematicides, abamectin and emamectin, were used to conduct on previously dsRNA-soaked nematodes. Thus, 200 nematodes were soaked in $500 \mu \mathrm{L}$ abamectin $(4.5 \mathrm{mg} / \mathrm{L})$ and emamectin $(0.3 \mathrm{mg} / \mathrm{L})$ solutions, respectively [43], in a $1.5 \mathrm{~mL}$ centrifuge tube. B. xylophilus without RNAi-treatment soaked in nematicides and $\mathrm{ddH}_{2} \mathrm{O}$, were used as controls. The Zeiss Axio Image M2 microscope was used to observe the vitality and morphology of B. xylophilus, and photographs were taken after the nematodes were soaked at $25^{\circ} \mathrm{C}$ for $24 \mathrm{~h}$.

\subsection{Statistical Analysis}

All assays were performed in triplicate as three independent trials. Results showed as the mean \pm standard deviation (SD) of three independent experiments were calculated using Microsoft Excel. The statistical significance was determined using SPSS Statistics 17.0 software (IBM China Company Ltd., Beijing, China) to perform the paired $t$-tests. Asterisks indicate statistically significant differences $(* p<0.05, * * p<0.01$, Student's $t$-test).

\section{Acknowledgments}

This work was financially supported by the National Natural Science Fund of China (NO. 31270683), the Project for Natural Science Research of Jiangsu University in China (NO. 11KJA220002), and the Priority Academic Program Development of Jiangsu Higher Education Institutions (PAPD). Furthermore, we thank De-Wei Li, The Connecticut Agricultural Experiment Station, Windsor, CT, USA for critically reviewing the manuscript. 


\section{Author Contributions}

Xiao-Lu Xu: Study design, guarantor of integrity of entire study, experimental studies, manuscript preparation; Jian-Ren Ye and Lin Huang: Study design, data acquisition; Xiao-Qin Wu: Guarantor of integrity of entire study, manuscript final version approval.

\section{Conflicts of Interest}

The authors declare no conflict of interest.

\section{References}

1. Mamiya, Y. Pathology of the pine wilt disease caused by Bursaphelenchus xylophilus. Annu. Rev. Phytopathol. 1983, 21, 201-220.

2. Mota, M.M.; Braasch, H.; Bravo, M.A.; Penas, A.C.; Burgermeister, W.; Metge, K.; Sousa, E. First report of Bursaphelenchus xylophilus in Portugal and in Europe. Nematology 1999, 1, 727-734.

3. Penas, A.C.; Correia, P.; Bravo, M.A.; Mota, M.; Tenreiro, R. Species of Bursaphelenchus Fuchs, 1937 (Nematoda: Parasitaphelenchidae) associated with maritime pine in Portugal. Nematology 2004, 6, 437-453.

4. Fonseca, L.; Cardoso, J.M.S.; Lopes, A.; Pestana, M.; Abreu, F.; Nunes, N.; Mota, M.; Abrantes, I. The pinewood nematode, Bursaphelenchus xylophilus, in Madeira Island. Helminthologia 2012, 49, 96-103.

5. Wingfield, M.J.; Blanchette, R.A. The pine-wood nematode, Bursaphelenchus xylophilus, in Minnesota and Wisconsin: Insect associates and transmission studies. Can. J. For. Res. 1983, 13, 1068-1076.

6. Ceng, H.R.; Lin, M.S.; Ni, W.Q.; Fang, Z.D. First report of pine wilt disease from Pinus thunbergii Parl in Nanjing. For. Pest Dis. 1983, 4, 1-5.

7. Jones, J.T.; Moens, M.; Mota, M.; Li, H.; Kikuchi, T. Bursaphelenchus xylophilus: Opportunities in comparative genomics and molecular host-parasite interactions. Mol. Plant Pathol. 2008, 9, 357-368.

8. Kikuchi, T.; Jones, J.T.; Aikawa, T.; Kosaka, H.; Ogura, N. A family of glycosyl hydrolase family 45 cellulases from the pine wood nematode Bursaphelenchus xylophilus. FEBS Lett. 2004, 572, 201-205.

9. Kikuchi, T.; Shibuya, H.; Aikawa, T.; Jones, J.T. Cloning and characterization of pectatelyases expressed in the esophageal gland of the pine wood nematode Bursaphelenchus xylophilus. Mol. Plant Microbe Interact. 2006, 19, 280-287.

10. Coon, M.J.; Vaz, A.D.; Bestervelt, L.L. Cytochromes P450 2: Peroxidative reactions of diversozymes. FASEB J. 1996, 10, 428-434.

11. Werck, R.D.; Feyereisen, R. Cytochromes P450: A success story. Genome Biol. 2002, 6, 1-9.

12. Li, X.; Schuler, M.A.; Berenbaum, M.R. Molecular mechanisms of metabolic resistance to synthetic and natural xenobiotics. Annu. Rev. Entomol. 2007, 52, 231-253.

13. Schuler, M.A. P450s in plant-insect interactions. Biochim. Biophys. Acta 2011, 1814, 36-45. 
14. Nebert, D.W.; Russell, D.W. Clinical importance of the cytochromes P450. Lancet 2002, 360, 1155-1165.

15. Yue, L.; Yang, Y.; Wu, S.; Wu, Y. Cloning and mRNA expression levels of cytochrome P450 genes CYP6AE12 and CYP9A18 in the cotton bollworm, Helicover armigera (Hübner). Acta Entomol. Sin. 2007, 50, 234-240.

16. Yu, R.R. Molecular Characterization and Functional Analysis of Three Cytochrome P450 Genes from Locusta migratoria. Master Thesis, Shanxi University, Taiyuan, China, 2012.

17. Xu, Y.Q. Molecular Cloning, Sequence Analysis and Expression of Cytochrome P450 Gene in Tribolium castaneum (Herbst). Master Thesis, Southwest University, Chongqing, China, 2009.

18. Qiu, X.; Wu, X.; Huang, L.; Tian, M.; Ye, J. Specifically expressed genes of the nematode Bursaphelenchus xylophilus involved with early interactions with pine trees. PLoS One 2013, 8, e78063.

19. Yang, B.J. Advance in research of pathogenetic mechanism of pine wood nematode. For. Pest Dis. 2002, 1, 27-31.

20. Dropkin, V.H.; Foudin, A.; Kondo, E.; Linit, M.; Smith, M.; Robbins, K. Pine wood nematode: A threat to U.S. forest. Plant Dis. 1981, 65, 1022-1027.

21. Taiz, L. Plant cell expansion: Regulation of cell wall mechanical properties. Annu. Rev. Plant Physiol. 1984, 35, 585-657.

22. Qin, L.; Kudla, U.; Roze, E.H.; Goverse, A.; Popeijus, H.; Nieuwland, J.; Overmars, H.; Jones, J.T.; Schots, A.; Smant, G.; et al. Plant degradation: A nematode expansin acting on plants. Nature 2004, 427, 30-30.

23. Lin, S.F.; Guo, L.; Jian, H.; Zhang, G.Z. Construction of specific cDNA library and cloning of expansin gene from the ante-rior end of Bursaphelenchus xylophilus. Acta Phytopathol. Sin. 2008, 3, 283-291

24. Kang, J.S.; Koh, Y.H.; Moon, Y.S.; Lee, S.H. Molecular properties of a venom allergen-like protein suggest a parasitic function in the pine wood nematode Bursaphelenchus xylophilus. Int. J. Parasitol. 2012, 42, 63-70.

25. Sorensen, J.G.; Kristensen, T.N.; Loeschcke, V. The evolutionary and ecological role of heat shock proteins. Ecol. Lett. 2003, 6, 1025-1037.

26. Dai, S.M.; Cheng, X.Y.; Xiao, Q.M.; Xie, B.Y. Cloning and prokaryotic expression of Hsp70 from pine wood nematode (Bursaphelenchus xylophilus). Acta Phytopathol. Sin. 2007, 37, 512-519.

27. Sun, Y.; MacRae, T.H. The small heat shock proteins and their role in human disease. FEBS J. 2005, 272, 2613-2627.

28. Liu, L.H.; Wang, F.; Wang, B.Y.; Ma, L; Yang, Y.; Cui, W.C. Gene cloning and protein structure implications of a Bx-sHSP16A from Bursaphelenchus xylophilus. Chin. Agric. Sci. Bull. 2013, 29, $40-45$.

29. Terriere, L.C. Enzyme induction, gene amplification and insect resistance to insecticides. In Pest Resistance to Pesticides; Springer: New York, NY, USA, 1983; pp. 265-297.

30. Batar, M.; Schalk, M.A.; Pierrel, A.; Zimmerlin, F.D.; Werck, R.D. Regulation of the cinnamate 4-hydrolase (CYP73A1) in Jersusalem artichoke tubers in reponse to wounding and chemical treatments. Plant Physiol. 1997, 113, 951-959. 
31. Terriere, L.C. Induction of detoxication enzymes in insects. Annu. Rev. Entomol. 1984, 29, 71-88.

32. Gonzalez, F.J.; Nebert, D.W. Evolution of the P450 gene superfamily: Animal-plant "warfare", molecular drive and human genetic differences in drug oxidation. Trends Genet. 1990, 6, 182-186.

33. Nelson, D.R.; Kamataki, T.; Waxman, D.J.; Guengerich, F.P.; Estabrook, R.W.; Feyereisen, R.; Gonzalez, F.J.; Coon, M.J.; Gunsalus, I.C.; Gotoh, O.; et al. The P450 superfamily: Update on new sequences, gene mapping, accession numbers, early trivial names of enzymes, and nomenclature. DNA Cell Biol. 1993, 12, 1-51.

34. Santos, C.S.; Pinheiro, M.; Silva, A.I.; Egas, C.; Vasconcelos, M.W. Searching for resistance genes to Bursaphelenchus xylophilus using high throughput screening. BMC Genomics 2012, 13, doi:10.1186/1471-2164-13-599.

35. Fire, A.; Xu, S.; Montgomery, M.K.; Kostas, S.A.; Driver, S.E.; Mello, C.C. Potent and specific genetic interference by double-stranded RNA in Caenorhabditis elegans. Nature 1998, 391, 806-811.

36. Aravin, A.A.; Naumova, N.M.; Tulin, A.V.; Vagin, V.V.; Rozovsky, Y.M.; Gvozdev, V.A. Double-stranded RNA-mediated silencing of genomic tandem repeats and transposable elements in the D. melanogaster germline. Curr. Biol. 2001, 11, 1017-1027.

37. Wesley, S.V.; Helliwell, C.A.; Smith, N.A.; Wang, M.; Rouse, D.T.; Liu, Q.; Gooding, P.S.; Singh, S.P.; Abbott, D.; Stoutjesdijk, P.A.; et al. Construct design for efficient, effective and high-throughput gene silencing in plants. Plant J. 2001, 27, 581-590.

38. Sugimoto, A. High-throughput RNAi in Caenorhabditis elegans: Genome-wide screens and functional genomics. Differentiation 2004, 72, 81-91.

39. Urwin, P.; Lilley, C.; Atkinson, H. Ingestion of Double-stranded RNA by pre parasitic juvenile cyst nematodes leads to RNA interference. Mol. Plant Microbe Interact. 2002, 15, 747-752.

40. Tsalik, E.L.; Hobert, O. Functional mapping of neurons that control locomotory behavior in Caenorhabditis elegans. J. Neurobiol. 2003, 56, 178-179.

41. Oku, H.; Shiraishi, T.; Chikamatsu, K. Active defense as a mechanism of resistance in pine against pine wilt disease. Ann. Phytopathol. Soc. JPN 1989, 55, 603-608.

42. Zhu, L.H.; Ye, J.R.; Negi, S.; Xu, X.L.; Wang, Z.L.; Ji, J.Y. Pathogenicity of aseptic Bursaphelenchus xylophilus. PLoS One 2012, 7, e38095.

43. Lai, Y.X.; CHI, S.Y.; Wang, Y.H.; Zhang, Y.F.; Han, Z.M. Pesticide toxicity and selection for the pine wood nematode. J. Zhejiang Agric. For. Univ. 2011, 28, 479-485.

(C) 2015 by the authors; licensee MDPI, Basel, Switzerland. This article is an open access article distributed under the terms and conditions of the Creative Commons Attribution license (http://creativecommons.org/licenses/by/4.0/). 